\title{
Quadrivalvar Rheumatic Cardiopathy in Tetralogy of Fallot in an Adult -A Case Report
}

\author{
Ramachandran Muthiah \\ Thoothukudi Medical College Hospital, Thoothukudi, India \\ Email: cardioramachandran@yahoo.co.uk
}

Received 4 May 2016; accepted 10 June 2016; published 13 June 2016

Copyright ( 2016 by authors and Scientific Research Publishing Inc.

This work is licensed under the Creative Commons Attribution International License (CC BY).

http://creativecommons.org/licenses/by/4.0/

\section{c) (i) Open Access}

\begin{abstract}
Rheumatic involvement of all four heart valves is uncommon and its association with congenital heart disease is very rare. Tetralogy of Fallot is a frequent cyanotic congenital heart disease with a survival beyond middle age. Background of this case report described the rheumatic involvement of all four heart valves (quadrivalvar rheumatic cardiopathy) with stenotic lesions of semilunar valves (aortic and pulmonary valves) and regurgitant lesions of atrioventricular valves (mitral and tricuspid valves) in Tetralogy of Fallot in a 48-year old asymptomatic female, detected by transthoracic two dimensional echocardiography in Thoothukudi region of India.
\end{abstract}

\section{Keywords}

Tetralogy of Fallot, Rheumatic Cardiopathy, All Four Heart Valves, Echocardiography, Current Research Status

\section{Introduction}

Incidence of valvular involvement in rheumatic heart disease (RHD) is the function of hemodynamic pressures and shear stresses on the exposed valves. The sparing of pulmonary valve in rheumatic process is usually attributed to low pressure and shear stress on this valve, but it does not explain in patients with severe pulmonary hypertension secondary to left sided valvular disease and lack of pulmonary involvement. When the transplanted pulmonary valve is placed in aortic position in pulmonary valve autograft Ross' procedure, it is susceptible to rheumatic valvulitis similar to the native aortic valve [1]. This reinforces the theory that no valve is immune to rheumatic process.

Involvement of all four valves is an uncommon feature of rheumatic heart disease [2]. There is a high inci- 
dence of multivalvar damage when Ascoff bodies are identified at necropsy [3]. There are few reports available in the literature describing the rheumatic lesions of all four heart valves [4]. When all the four valves are affected by rheumatic disease, the lesion is usually one of stenosis and the majority of the reported cases are females. Kumar et al. [5] have quoted only 10 cases of quadrivalvar rheumatic heart disease in the English literature in 1985. In 1987, Hossack et al. [6] reported the case of a patient with rheumatic involvement of all valves treated with quadruple valve replacement and 12 cases have been reported upto 2005. In 2012, Cao and colleagues reported a 11-year follow-up study of a patient with subacute rheumatic endocarditis who underwent quadruple valve replacement [7]. Coexistent rheumatic disease in patients with congenital heart disease was known to occur [8] [9]. Tetralogy of Fallot (TOF) is the most common congenital heart disease seen beyond infancy and childhood with about $5 \%$ of patients surviving to the age of 40 years.

Rheumatic involvement of all four heart valves (quadrivalvar rheumatic cardiopathy) is uncommon in tetralogy of Fallot and so this case had been reported.

\section{Case Report}

A 48-year old asymptomatic female was referred for echocardiographic evaluation with a history of cyanosis from early childhood and a precordial murmur. Her pulse rate was 96 bpm and blood pressure was 110/70 mmHg. She had some frequent episodes of upper respiratory infection during childhood and treated with antibiotics, but penicillin prophylaxis was not given. She had delivered two healthy children normally, aged 10 and 13 years. General examination revealed central cyanosis and clubbing. Physical examination revealed a grade 3/6 systolic murmur in the left second intercostal space and a soft, single second heart sound. ECG and X-ray chest revealed right ventricular hypertrophy, consistent with Tetralogy of Fallot. Blood chemistry revealed a positive ASO (anti-streptolysin $\mathrm{O}$ ) test suggesting the reactivation of rheumatic process following a recurrent episode of streptococcal infection. She was advised penicillin prophylaxis and periodic follow up. Transthoracic 2D echocardiography revealed a large malaligned ventricular septal defect (VSD) with valvular pulmonary stenosis suggesting tetralogy of Fallot and a thickened, calcified pulmonary and aortic valves with stenosis, thickened and calcified mitral and tricuspid valves with regurgitation suggesting quadrivalvar rheumatic cardiopathy as shown in Figures 1-8.

\section{Discussion}

The prevalence rate of rheumatic heart disease (RHD) is 0.5 - 0.67 per thousand in India [10]. The risk of coincident rheumatic disease in patients with tetralogy of Fallot was described in the literature. Rheumatic mitral stenosis was reported in an adult male, aged 35 years with tetralogy of Fallot at Visakhapatnam in India [11] and rheumatic involvement of all four valves in tetralogy of Fallot was also reported in a 14-year-old male [12].

\subsection{Echocardiography}

Transthoracic echocardiography provides an early diagnosis of rheumatic involvement of all four heart valves (quadrivalvar rheumatic cardiopathy). There are only few reports of echocardiographic diagnosis of stenotic involvement of all four heart valves due to rheumatic etiology [13] [14]. Bandin et al. stated that 3.6\% of hearts with rheumatic disease show organic lesions of the pulmonary valve based on autopsy series and reported one patient having quadrivalvar rheumatic disease, diagnosed preoperatively by echocardiography [15]. Thus, echocardiography is useful for confirming clinical findings and allows assessment of the severity of valvular stenosis and regurgitation [16].

In this case, transthoracic 2D echocardiography revealed a large malaligned ventricular septal defect as shown in Figure 1 and Color Doppler imaging in Figure 5, with valvular pulmonary stenosis as in Figure 6 and Figure 7, suggesting the tetralogy of Fallot. The classical echocardiographic features of rheumatic involvement of valves such as thickened leaflets, commissural fusion with calcific deposits noticed in pulmonary and aortic valves as shown in Figure 3, thickened mitral and tricuspid valves as in Figure 4, valvular regurgitation involving the thickened mitral and tricuspid valves as in Figure 8, suggesting the quadrivalvar rheumatic cardiopathy in tetralogy of Fallot. Stenotic lesions are predominant and severe in semilunar valves (aortic and pulmonary valves) due to simultaneous exposure of semilunar valves to the equal pressure gradients in the ventricles and regurgitant lesions are predominant in atrioventricular valves (mitral and tricuspid valves) is a characteristic feature of rheumatic involvement in tetralogy of Fallot of this patient. 


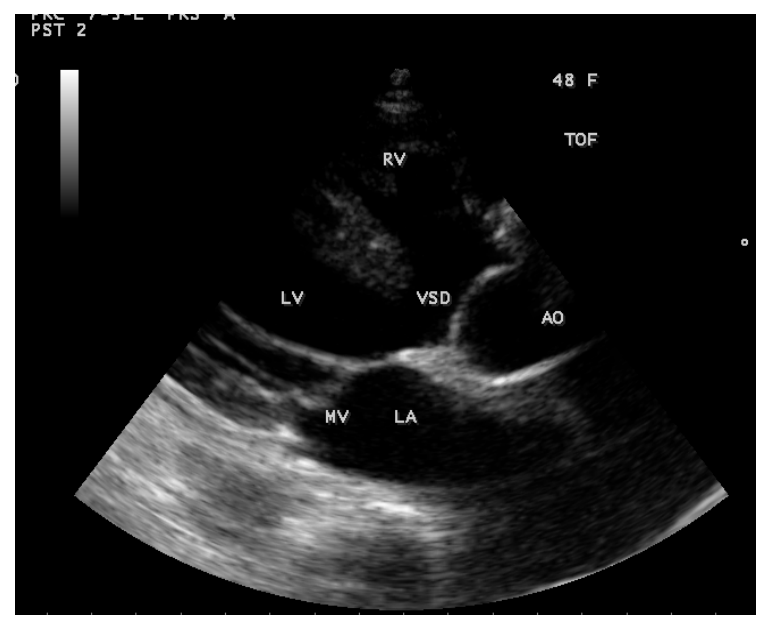

Figure 1. Parasternal long axis view showing the large malaligned ventricular septal defect (VSD).

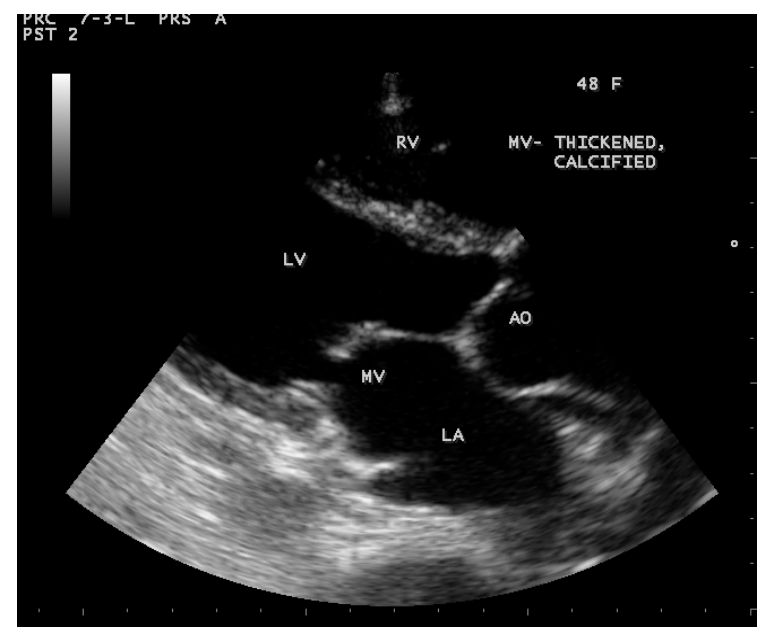

Figure 2. Parasternal long axis view showing the thickened and calcified mitral valve.

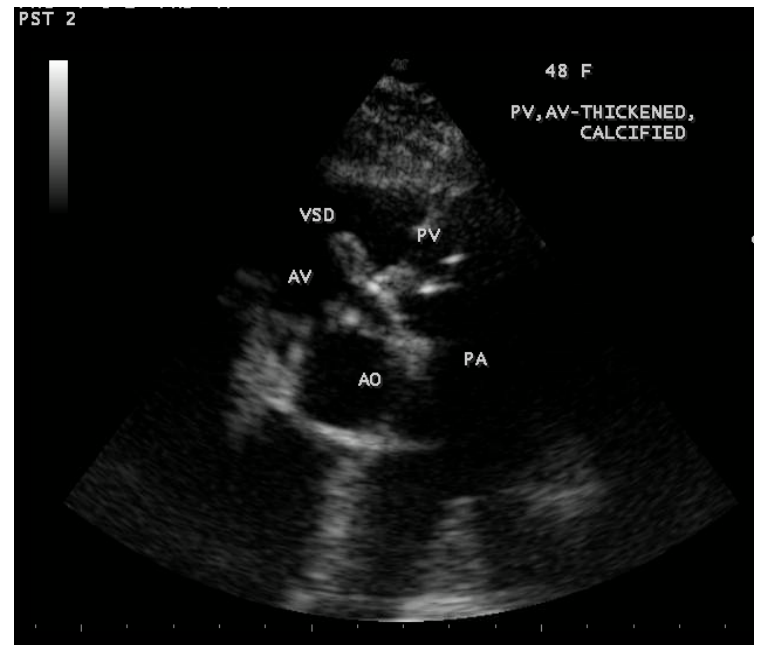

Figure 3. Short axis view showing the thickened and calcified pulmonary and aortic valves. 


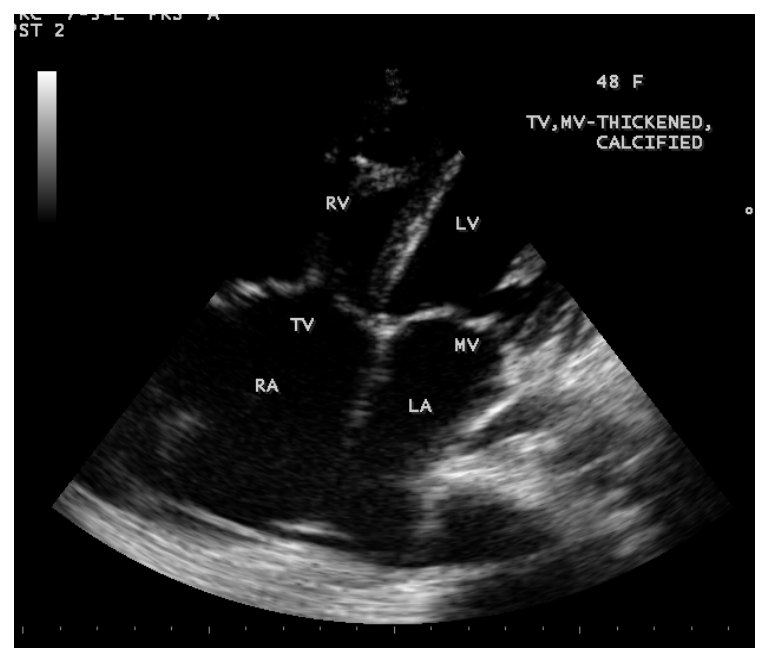

Figure 4. Apical four chamber view showing the thickened and calcified mitral and tricuspid valves.

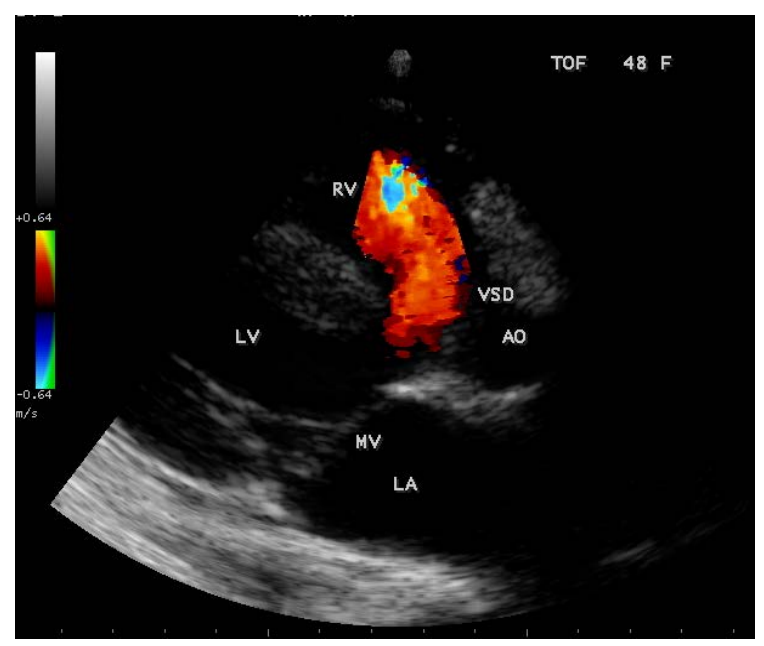

Figure 5. Color-Doppler imaging showing the malaligned VSD.

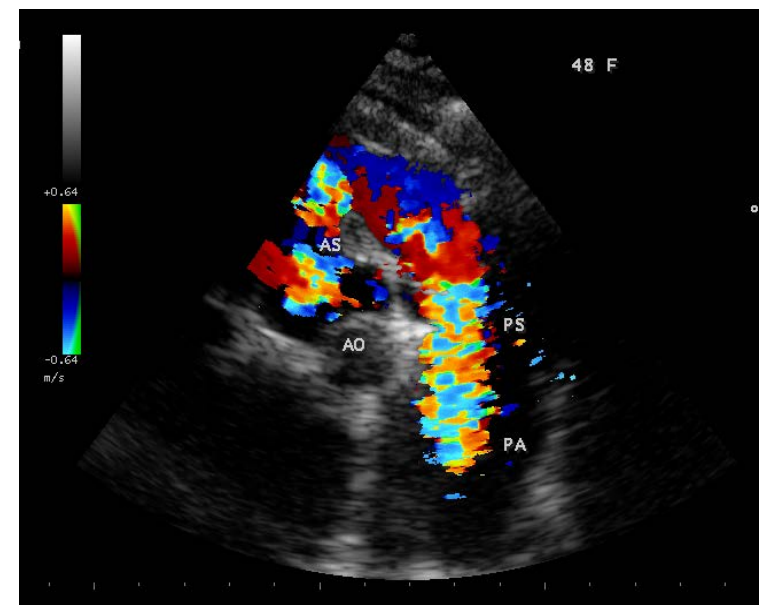

Figure 6. Color Doppler imaging showing the pulmonary and aortic stenosis in short axis view. 


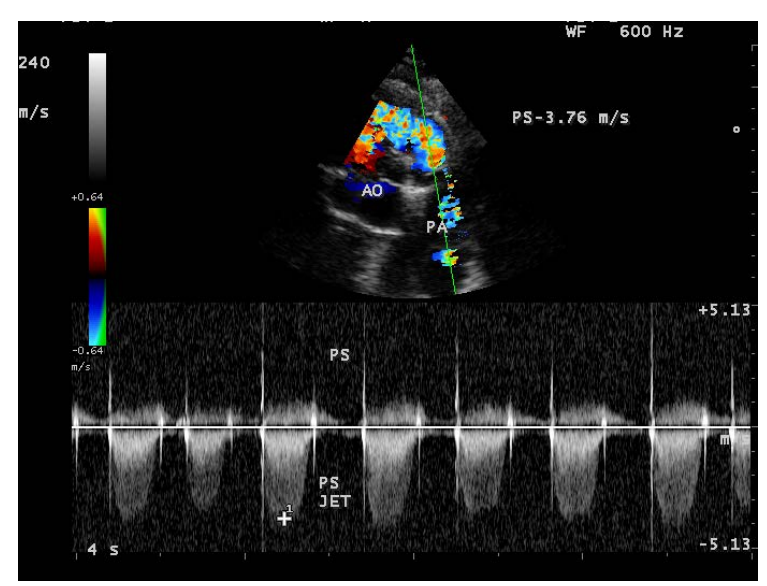

Figure 7. Continuous wave Doppler (CW) imaging showing the pulmonary stenosis jet.

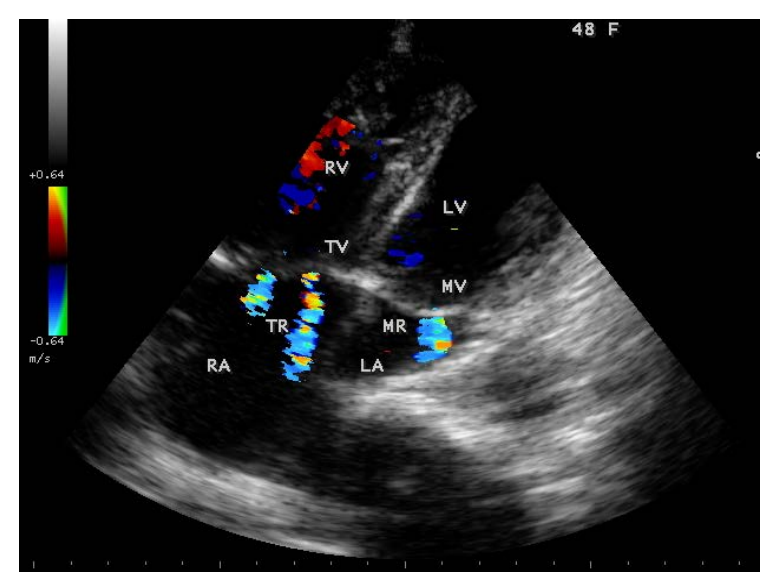

Figure 8. Color Doppler imaging showing the mitral and tricuspid regurgitation in apical four chamber view.

\subsection{Penicillin Prophylaxis}

Primary prophylaxis to eradicate the streptococcal infection and secondary prophylaxis to prevent the recurrent episodes are indicated as a therapeutic and preventive measures for RHD (Rheumatic Heart Disease) patients. Primary prophylaxis also serves as the first course of secondary prophylaxis. Ideally, continue prophylaxis indefinitely and sometimes life long, because recurrent streptococcal infections and rheumatic fever cases occur at any age in endemic areas and it should be maintained for those with clinically significant RHD for at least ten years after the last episode. Long-acting penicillin is of particular value in patients with a high risk of recurrence of rheumatic fever. An injection of 1.2 million units of benzathine penicillin G intramuscularly every 3 weeks [17] is recommended for this patient at least for ten years and preferably life long.

Thus, the recognition of rheumatic involvement of heart valves in tetralogy of Fallot is significant in endemic areas of RHD and the penicillin prophylaxis may prevent further deterioration in this case.

\subsection{Current Research Status}

\subsubsection{In Pathogenesis}

The organism group A beta-hemolytic streptococcus (streptococcus pyogenes), attach the epithelial cells of the upper respiratory tract and produce battery of enzymes, allowing them to damage and invade human tissues. Only infections of the pharynx have been shown to initiate or reactivate rheumatic fever in $0.3 \%-3 \%$ of cases. However, epidemiological association in certain population have shown that group A streptococcus impetigo could predispose to or cause rheumatic fever as well [18]. Streptococcal proteins display molecular mimicry 
recognized by the immune system, especially bacterial M-proteins and human cardiac antigens such as myosin [19] and valvular endothelium. Currently emm typing is felt to be more discriminating than M typing [20]. Antimyosin antibody recognizes laminin, an extracellular matrix alpha-helix coiled protein, which is part of the valve basement membrane structure. T-cells that are responsive to the streptococcal M-protein infiltrate the valve through the valvular endothelium, activated by the binding of anti-streptococcal carbohydrate with the release of tumor necrosis factor (TNF) and interleukins [21]. Thus, cross-reactive antibodies bind to cardiac tissue, facilitate infiltration of streptococcal-primed CD4+T cells, which then triggers an autoimmune reaction and releasing inflammatory cytokines (TNF- $\alpha$ and IFN-gamma). Because few IL-4 producing cells are present in valvular tissue, inflammation persists, leading to valvular lesion. A study reported that the increased expression of Th 17 cell-associated cytokines might play an important role in the pathogenesis and development of rheumatic heart disease [22]. In chronic disease, there is thickening and fibrosis of the valve resulting in stenosis, or less commonly regurgitation.

In utero precursors predisposing to rheumatic heart disease have also been proposed [23] [24]. Eriksson et al. suggest increased spiraling of the umbilical cord may increase the risk of rheumatic heart disease secondary to presumed changes in hemodynamic conditions during the formation of the mitral valve [25].

Familial studies of rheumatic heart disease suggest a vulnerable population with increased risk of having relationship between the development of rheumatic fever and human leukocyte antigens (HLA)-DR subtypes have been found [26]. HL-DR3 was present more frequently in rheumatic fever patients in India, DR-1 in South Africa, DR-2 in African-American population, DR-4 in Cauccasian and DQW2 in Asian Patients.

\subsubsection{Probiotic Treatment}

To find a solution to outbreaks of group A streptococcal (GAS) sore throat, a probiotic treatment was developed at Otago University. The BLIS K 12 probiotic specific to the throat and mouth, sold as "BLIS throat guard" was trialled in selected primary schools in Whakatane and Kawerau where the rheumatic fever has been an increasing problem and a school sore throat rheumatic fever programme has been running since 2010. The term antibiotics points to treatments which kill the microbes and the term probiotic refers to being "in support of life" as the mechanism supports the re-setting of the microbial biome, through growing beneficial microbes. BLIS K 12 populate the mouth and throat with a beneficial strains of streptococcus salivarius. When antibiotics were followed by taking the BLIS K 12 probiotic lozenges daily for 30 days, encouraging results were seen in school children with clearance of streptococcal infection from the throat up to 3 months [27].

\subsubsection{Group A Streptococcal Vaccine Development}

Efforts to produce a vaccine against streptococcus pyogenes began several decades ago, and different models have been proposed as M-protein based vaccines (N-and C-terminal portion), the major antigen of streptococcus pyogenes, the non-M protein based vaccine and other potential GAS vaccines such as Spe (streptococcal pyrogenic exotoxin) $\mathrm{A}$ and $\mathrm{C}$.

StreptAvax is a M-protein based, multivalent type-specific vaccine, consists of a sequence of short peptides from the $\mathrm{N}$ terminal region of multiple different emm type strains in tandem, linked together using unique restriction sites. It may not produce sufficient and long-lasting protection in countries with highly endemic GAS diseases.

Streptlncor, a vaccine candidate peptide, comprising 55 aminoacid residues of the C-terminal portion of the M protein and encompassing both the T-and B-cell protective epitopes. Streptlncor overlapping peptides induced cellular and humoral immune responses of individuals bearing different HLA class II molecules of the macrophage to $\mathrm{T}$ lymphocytes via the T-cell receptor (TCR) and it could be considered as an immunogenic and safe vaccine. The safety of this vaccine was assessed using DR2, DR4, DQ6 and DQ 8 HLA class II transgenic mice.

StreptAnova ${ }^{(\mathrm{R})}$ multivalent vaccine is composed of four recombinant proteins containing protective peptides from 30 streptococcal serotypes that account for the vast majority of infections in North America and Europe. Phase I trial is ongoing as 3 injections over 6 months, with a one-year follow-up to assess the immune response to the vaccine [28].

\subsubsection{Global Research Priorities}

It is universally accepted that the most cost-effective approach to RHD (Rheumatic heart disease) control is delivery of secondary prophylaxis and improved clinical care of patients, using register-based RHD control pro- 
grams as in New Zealand and Australia. An implantable form of penicillin could be a major advance. Naltrexone penicillin implants provide a promising model, given that the equivalent daily dose is similar to what would be required for penicillin [29]. Genetic studies to identify the nature of host susceptibility to detect the vulnerable groups and development of vaccine, screening echocardiography to detect subclinical carditis and to implement secondary prophylaxis are the priority measures in endemic areas.

\subsubsection{Role of Statins}

Early medical therapy with statins in patients with rheumatic heart disease showed a significantly slower progression of the disease as found in a recent study done in Europe on 315 patients with rheumatic mitral stenosis in 2010 [30] and reducing LDL-C (low-density lipoprotein cholesterol) may help to prevent aortic valve disease [31] as found by Smith et al. in 2014.

\section{Conclusion}

Quadrivalvar rheumatic cardiopathy with stenotic lesions in semilunar valves and regurgitant lesions in atrioventricular valves is a characterized feature detected by 2D echocardiography in a 48-year old female with tetralogy of Fallot in the tropical district of Thoothukudi in India in the year 2016.

\section{References}

[1] De Vries, H., Bogers, J.J.C., Schoof, P.H., Machtar, B., Spitaels, S.E,C., Periroth, M.G., Hess, J. and Bos, E. (1994) Pulmonary Autograft Failure Caused by Relapse of Rheumatic Fever. Annals of Thoracic Surgery, 57, 750-751. http://dx.doi.org/10.1016/0003-4975(94)90584-3

[2] Paraskos, J.A. (1987) Combined Valvular Disease. In: Dalen, J.E. and Alpert, J.S., Eds., Valvular Heart Disease, 2nd Edition, Little, Brown, Boston, 439-508.

[3] Roberts, W.C. and Virmani, R. (1978) Aschoff Bodies at Necropsy in Valvar Heart Disease: Evidence from an Analysis of 543 Patients over 14 Years of Age. Circulation, 57, 803-807. http://dx.doi.org/10.1161/01.CIR.57.4.803

[4] Gialloreto, O., Aenichide, N. and Allard, P.P. (1961) Stenotic Involvement of All Four Heart Valves, Report of Three Cases. American Journal of Cardiology, 7, 865-873. http://dx.doi.org/10.1016/0002-9149(61)90407-6

[5] Kumar, A.S., Iyer, K.S. and Chopra, P. (1985) Quadrivalvar Heart Disease. International Journal of Cardiology, 7, 6669. http://dx.doi.org/10.1016/0167-5273(85)90177-9

[6] Hossack, K.F., Hopeman, A.R. and Sutherland, E.W. (1987) Long-Term Follow-Up of a Patient with Quadruple Valve Replacement. Texas Heart Institute Journal, 14, 315-317.

[7] Cao, Y., Gu, C., Sun, G., et al. (2012) Quadruple Valve Replacement with Mechanical Valves, an 11-Year Follow-Up Study. Heart Surgery Forum, 15, E145-E149. http://dx.doi.org/10.1532/HSF98.20111124

[8] Bokhandi, S., Tullu, M.S., Shaharao, V.B., Bavdekar, S.B. and Kamat, J.R. (2002) Congenital Heart Disease with Rheumatic Fever and Rheumatic Heart Disease, a Coincidence or an Association? Journal of Postgraduate Medicine, 48, 238.

[9] Mohan, J.C., Arora, R. and Khalilullah, M. (1991) Double Outlet Right Ventricle with Calcified Rheumatic Mitral Stenosis. Indian Heart Journal, 43, 397-399.

[10] Savitri, S. (2007) Rheumatic Heart Disease, Is It Declining in India? Indian Heart Journal, 59, 9-10.

[11] Krishna, C.S., et al. (2008) Tetralogy of Fallot with Rheumatic Mitral Stenosis, a Case Report. Journal of Medical Case Reports, 2,127. http://dx.doi.org/10.1186/1752-1947-2-127

[12] Mansur, A.J., Grinberg, M., Lopes, E.A., Ebaid, M., Rangel, F.A., Yamano, J.S. and Decourt, L.V. (1980) Acute Rheumatic Involvement of All Four Cardiac Valves in a Case of Tetralogy of Fallot. Arquivos Brasileiros de Cardiologia, 35, 499-502.

[13] Krishnamoorthy, K.M. (2002) Rheumatic Stenosis of All Four Valves. Texas Heart Institute Journal, 29, $224-225$.

[14] Jai Shanker, K., Jaiswal, P.K. and Cherian, K.M. (2005) Rheumatic Involvement of All Four Cardiac Valves. Heart, 91, e 50 .

[15] Bandin, M.A., Vargas Barron, J., Keims, C., et al. (1990) Echocardiographic Diagnosis of Rheumatic Cardiopathy Affecting All Four Cardiac Valves. American Heart Journal, 120, 1004-1007. http://dx.doi.org/10.1016/0002-8703(90)90230-U

[16] Vasan, R.S., Shrivastava, S., Vijayakumar, M., Narang, R., Lister, B.C. and Narula, J. (1996) Echocardiographic Evaluation of Patients with Acute Rheumatic Fever and Rheumatic Carditis. Circulation, 94, 73-82. 
http://dx.doi.org/10.1161/01.CIR.94.1.73

[17] Lue, H.C., Wu, M.H., Wang, J.K., Wu, F.-F. and Wu, Y.-N. (1994) Long-Term Outcome of Patients with Rheumatic Fever Receiving Benzathine Penicillin G Prophylaxis Every Three Weeks versus Every Four Weeks. Journal of Pediatrics, 125, 812-816. http://dx.doi.org/10.1016/S0022-3476(06)80188-5

[18] Parks, T., Smeesters, P.R. and Steer, A.C. (2012) Streptococcal Skin Infection and Rheumatic Heart Disease. Current Opinion in Infectious Disease, 25, 145-153. http://dx.doi.org/10.1097/QCO.0b013e3283511d27

[19] Veasy, L.G., Wiedmeier, S.E., Orsmond, G.S., et al. (1987) Resurgence of Acute Rheumatic Fever in the Intermountain Area of the United States. New England Journal of Medicine, 316, 421-427. http://dx.doi.org/10.1056/NEJM198702193160801

[20] Pickering, L.K. (2009) Rheumatic Fever, Red Book Report of the Committee on Infectious Diseases. 28th Edition, American Academy of Pediatrics, 616-628.

[21] Guilherme, L., Cury, P., Demarchi, L.M., Coelho, V., Abel, L., Lopez, A.P., et al. (2004) Rheumatic Heart Disease, Proinflammatory Cytokines Play a Role in the Progression and Maintainance of Valvular Lesions. American Journal of Pathology, 165, 1583-1591. http://dx.doi.org/10.1016/S0002-9440(10)63415-3

[22] Wen. Y., Zeng, Z., Gui, C., Li, L. and Li, W. (2015) Changes in the Expression of TH 17 Cell-Associated Cytokines in the Development of Rheumatic Heart Disease. Cardiovascular Pathology, 24, 382-387. http://dx.doi.org/10.1016/j.carpath.2015.07.006

[23] Mukhopadhyay, S., Varma, S., Gade, S., Yusuf, J., Trehan, V. and Tyagi, S. (2013) Regulatory T-Cell Deficiency in Rheumatic Heart Disease: A Preliminary Observational Study. The Journal of Heart Valve Disease, 22, 118-125.

[24] Bas, H.D., Baser, K., Yavuz, E., Bolayir, H.A., Yaman, B. and Unlu, S. (2014) A Shift in the Balance of Regulatory T and T Helper 17 Cells in Rheumatic Heart Disease. Journal of Investigative Medicine, 62, 78-83. http://dx.doi.org/10.2310/JIM.0000000000000023

[25] Eriksson, J.G., Kajantie, E., Phillips, D.I., Osmond, C., Thomburg, K.L. and Barker, D.J. (2013) The Developmental Origins of Chronic Rheumatic Heart Disease. American Journal of Human Biology, 25, 655-658. http://dx.doi.org/10.1002/ajhb.22425

[26] Hafez, M., Chakravarti, A., El-Shennawy, F., El-Morsi, Z., El-Sallab, S.H., Al-Tanhary, Y., et al. (1985) HLA Antigen and Acute Rheumatic Fever. Genetic Epidemiology, 2, 273-282. http://dx.doi.org/10.1002/gepi.1370020305

[27] Un-Doctored (2016) Positive Signs in Search to Solve Rheumatic Fever and Group A Streptococcal Sore Throat. Media Release From, Bachelor of Library and Information Science (BLIS), 03.

[28] Guilherme, L., Ferreira, F.M., Kohler, K.F., Postol, E. and Kalil, J. (2013) A Vaccine against Streptococcus Pyogenes, American Journal of Cardiovascular Drugs, 13, 1-4. http://dx.doi.org/10.1007/s40256-013-0005-8

[29] Ngo, H.T., Arnold-Reed, D.E., Hansson, R.C., Tait, R.J. and Hulse, G.K. (2008) Blood Naltrexone Levels over Time Following Naltrexone Implants. Progress in Neuro-Psycho Pharmacology and Biological Psychiatry, 32, 23-28. http://dx.doi.org/10.1016/j.pnpbp.2007.06.007

[30] Antonini-Canterin, F., Moura, L.M, Enache, R., Leiballi, E., Pawan, D. and Pizza, R. (2010) Effect of Hydroxyl Methyl Glutaryl Coenzyme-A Reductase Inhibitors on the Long-Term Progression of Rheumatic Mitral Valve Disease. Circulation, 121, 2130-2136.

[31] Smith, J.G., Luk, K., Schulz, C.A., et al. (2014) Association of Low-Density Lipoprotein Cholesterol-Related Genetic Variants with Aortic Valve Calcium and Incident Aortic Stenosis. Journal of American Medical Association (JAMA), 312, 1764-1771. 